\title{
Comparação entre a função do direito nas obras Teoria Geral do Direito e o Marxismo, de Eugeny Pasukanis, e em The Rule of Law, de Franz Neumann. ${ }^{1}$
}

Flavio Marques Prol

\section{Resumo:}

Por meio da análise das principais obras de Pasukanis e Neumann, o objetivo deste ensaio é demonstrar como a visão sobre a função do direito nos dois pensadores, ao contrário do que defendem grande parte de seus leitores, é complementar e não inconciliável.

Palavras-chave: Franz Neumann, Eugeny Pasukanis, Emancipação, Função do direito

I Tendo em vista os objetivos deste trabalho - a especificidade do papel do direito nas obras supracitadas, por conta das diferentes visões sobre a emancipação - vale ressaltar que outras obras de ambos os autores não serão discutidas e nem mesmo abordadas neste texto. 


\section{Introdução}

Eugeny Pasukanis era Vice-comissário do Povo para a Justiça na extinta URSS quando escreveu seu Teoria Geral do Direito e o Marxismo. O soviético escrevia em um período ainda inicial do pós-Revolução russa de I9I7, e um governo socialista, de transição para o "comunismo evoluído", era pensado pelos diversos intelectuais e políticos que governavam o país. As teses apresentadas pelo autor, colocando-o contra a possibilidade de o Estado soviético apresentar um direito proletário, fizeram-no sofrer perseguições políticas após a ascensão de Stálin ao poder. E mesmo com a apresentação de autocríticas duvidosas da perspectiva intelectual, Pasukanis foi executado em janeiro de $1937 .{ }^{2}$

Por sua vez, Franz Neumann tem uma história muito diferente. Quando escrevia The Rule of Law, de I937, ele estava na Inglaterra e esse texto serviu como sua Tese de Doutorado. Integrante do chamado "círculo externo" do Instituto de Pesquisas Sociais de Frankfurt, Neumann, em anos anteriores ao da formulação dessa tese, era então participante dos debates em torno da preocupação em formular uma Teoria Crítica da Sociedade, como proposta por Max Horkheimer no início de seus trabalhos como diretor desse Instituto. Ocorre que, para além de suas divergências com Horkheimer, Neumann viveu o conturbado período de ascensão do nazismo na Alemanha, fato que permeou toda a sua produção intelectual. ${ }^{3}$

Dando atenção aos dois textos, porém não nos esquecendo dos contextos individuais, partiremos da tese de que a ideia de emancipação é diferente para cada teórico, e tentaremos demonstrar que é exatamente tal disparidade que provoca diagnósticos distintos quanto ao papel do direito na sociedade capitalista. Dessa forma, concebendo a visão de Pasukanis sobre emancipação como sendo não só a superação do modo de produção econômico capitalista, mas do próprio modo de produção de vida que se tem sob a égide do capitalismo, defende-se que o autor historiciza o papel do direito. Por outro lado, acreditase que em Neumann a visão de emancipação, pelo menos na obra supracitada, limita-se a uma realização da propriedade comunal, o que pode induzir a se pensar o direito como uma categoria ahistórica. ${ }^{4}$

\footnotetext{
2 Para mais: NAVES, 2000.

3 Para mais: RODRIGUEZ, 2004.

4 Em termos gerais, Neumann observa como o direito suporta o pluralismo político, caso entendamos o direito como garantidor de um mínimo de liberdade frente à atuação estatal e atuante por normas gerais. Dessa forma, vê que as instituições jurídicas permitem o surgimento do que podem ser nomeados como "espaços de disputa", dos quais as classes exploradas poderiam utilizar para se beneficiar materialmente e mesmo alterar a estrutura econômica, sem a necessidade de se desconsiderar os ganhos materiais oriundos da racionalidade jurídica.
} 
Normalmente, identifica-se Pasukanis com uma visão instrumental do direito e Neumann como um defensor da forma jurídica a priori. No entanto, neste trabalho, defende-se que Pasukanis não desconsidera necessariamente o direito como um fenômeno essencial para se possibilitar a transição para uma sociedade emancipada e que Neumann poderia concordar com a emancipação provocando a superação da forma jurídica, ainda que esse não fosse seu objetivo ao escrever o livro analisado. Portanto, defende-se que os dois autores não são inconciliáveis. ${ }^{5}$

\section{Emancipação em Pasukanis. Há espaço para o direito?}

Pasukanis entende que a transição da sociedade capitalista para uma sociedade emancipada conduz a uma superação da forma jurídica. Dessa forma, há a necessidade de se apontar as especificidades desse diagnóstico crítico e entendêlo, senão em toda sua extensão, parcialmente, ${ }^{6}$ para ser possível identificar as condições históricas que possibilitam e promovem a forma jurídica, lembrando que são essas mesmas condições que deixam de existir em um segundo momento (exatamente após a transição para a sociedade emancipada) e que propiciam um diagnóstico de superação do direito.

De início, é essencial compreender que na perspectiva da Teoria Geral do Direito e o Marxismo, o direito é tanto fenômeno ideológico quanto fenômeno objetivo. Tal caracterização da forma jurídica percorre toda a obra, sendo que ora são ressaltados aspectos objetivos, ora ideológicos, sendo impossível compreendê-la em sua totalidade sem ter essa dualidade em mente. Assim:

O princípio da subjetividade jurídica (assim entendemos o princípio formal da liberdade e da igualdade; da autonomia da personalidade etc.) não é somente um meio dissimulatório e um produto da hipocrisia burguesa na medida em que é oposto à luta proletária pela abolição de classes, contudo, não deixando de ser também um princípio

5 Um dos autores que vê Neumann e Pasukanis como inconciliáveis é, por exemplo, COLLINS, 200I 6 Nos termos deste trabalho, não focaremos em uma análise de todos os aspectos relevantes abordados por Pasukanis em sua obra, nem mesmo trabalharemos com outros escritos do pensador. O objetivo é tentar reproduzir somente a questão da emancipação e sua relevância para a caracterização da forma jurídica. O livro Marxismo e direito, do professor Márcio Bilharindo Naves, é uma importante análise do pensamento pasukaniano em perspectiva bem mais ampla e pormenorizada do que o presente texto, contando inclusive com o estudo de artigos escritos em russo e sem tradução disponível para o português, assim como a dissertação de mestrado de Vinicius Casalino, A teoria do direito de Pachukanis e pseudoconcreticidade, a qual utilizamos bastante para a análise da obra pasukaniana. 
realmente atuante, que se acha incorporado à sociedade burguesa desde que essa nasceu da sociedade feudal patriarcal e a destruiu [...] a vitória deste princípio não é apenas e tão-somente um processo ideológico (ou seja, um processo da ordem das ideias, das representações etc.), mas antes um real processo de transformação jurídica das relações humanas, que acompanha o desenvolvimento da economia mercantil e monetária (da economia capitalista, falando da Europa) e que engendra profundas e múltiplas modificações de natureza objetiva (PASUKANIS, I989, pp. 4-5).

A partir disso, pode-se então compreender o que o autor entende por forma jurídica: é a forma que media a relação dos produtores de mercadoria entre si. Isso porque pensar a forma jurídica a partir de suas formas abstratas (por exemplo, norma jurídica), ainda que seja possível, não permite a apreensão do fenômeno jurídico em sua essencialidade, inclusive em perspectiva histórica. ${ }^{7}$ Compreender a forma jurídica como conexa à circulação de mercadorias não é resultado de um "economicismo" ou "circulacionismo", como alguns críticos tentam postular. É explicar como o excedente do trabalho socialmente produzido no modo de produção capitalista é apropriado por meio da "troca de equivalentes" e historicizar o direito.

O que Pasukanis tenta demonstrar é que a forma jurídica não existe enquanto uma relação social específica. Não existe, em sua análise histórica, uma relação jurídica convivendo com outras relações sociais. A forma jurídica, na realidade, empresta sua "roupagem" à relação dos detentores de mercadoria entre si. Por isso, ele identifica no direito privado o cerne do seu estudo para compreender o desenvolvimento histórico do fenômeno jurídico e torna as categorias do contrato relação jurídica e de sujeito de direito centrais.

O pensamento pasukaniano considera que a explicação do fenômeno jurídico, caso utilize outras categorias além dessas, é insuficiente ou não atribui relevância a suas origens históricas. Para se apreender os momentos fundamentais do direito, portanto, não se faz necessário nem mesmo os conceitos de lei e Estado. No entanto, não se pode imaginar que tais conceitos não façam parte de uma problematização das consequências objetivas e ideológicas que o direito promove ao se desenvolver conjuntamente ao capitalismo.

O direito, antes do surgimento do Estado moderno, era similar a privilégios e funcionava como garantidor das relações comerciais e, a partir desse momento, jurídicas. ${ }^{8}$ Tinha explícito viés classista que protegia os mercadores e

7 Exatamente o erro cometido por positivistas, como Kelsen (importante jurista positivista do século XX). Ver: PASUKANIS, I989, p.I6.

8 Em seu capítulo 5, Direito e Estado, Pasukanis analisa a Europa feudal para demonstrar seu ponto de vista, ressaltando a condição próxima do privilégio instituída pelo "jus mercatorum” (o direito próprio dos mercadores). 
somente eles. A mudança que permite a todos os habitantes de um mesmo território se tornarem sujeitos de direito (ou seja, possíveis ou prováveis detentores de mercadoria) está necessariamente ligada à expansão dos limites da economia mercantil capitalista e, portanto, da possibilidade de segurança e manutenção interna da ordem pelo Estado moderno e não a uma motivação racional ou moral que iguale todos os indivíduos em uma categoria que se justificaria como inerente ao fato do homem possuir vontades. ${ }^{9}$ Assim, o advento do Estado moderno, antes que criador da forma jurídica, só assegura que esse passe a mediar maior quantidade de relações sociais.

Há, na realidade, uma abstração do próprio direito, que deixa de se evidenciar em sua base material para se tornar ele próprio abstrato:

Cada homem torna-se um homem em geral, cada trabalho torna-se trabalho social útil em geral, cada indivíduo torna-se um sujeito de direito abstrato. Ao mesmo tempo a norma assume, igualmente, a forma lógica acabada de lei geral abstrata...

No sistema lógico de conceitos jurídicos, o contrato nada mais é do que uma variedade do ato jurídico em geral, isto é, nada além do que um dos meios de manifestação concreta da vontade com a ajuda da qual o sujeito age na esfera jurídica que o cerca. Histórica e concretamente, o conceito de ato jurídico é, ao revés, extraído do de contrato. Fora do contrato os conceitos jurídicos de sujeito e vontade não são mais do que abstrações mortas. É apenas no contrato que tais conceitos existem autenticamente. Ao mesmo tempo, a forma jurídica, em seu aspecto mais simples e mais puro, recebe, igualmente, no ato de troca, um fundamento material (PASUKANIS, I989, p.94). ${ }^{\text {Io }}$

Há então a demonstração dos momentos fundamentais do direito e seu desenvolvimento histórico, que engloba as abstrações oriundas do surgimento do Estado moderno e suas consequências objetivas (a "roupagem" jurídica sendo transportada para outras relações sociais, por exemplo) e ideológicas (as abstrações jurídicas que provocam maior confusão que esclarecimento para a compreensão do fenômeno jurídico, por exemplo).

9 Ideia defendida pelos "juristas burgueses", que consideram que os indivíduos são sujeitos de direito quando possuem vontade determinante.

IO É a partir dessa conceituação histórica que Pasukanis defende que os conceitos direito subjetivo e direito objetivo, direito público e direito privado sejam superados. Em seus termos, fica evidente que "o direito subjetivo é o fato primário, pois se assenta, em última instância, sobre interesses materiais que existem independentemente de regulação externa, consciente da vida social” (PASUKANIS, p. 70, I989) e que "o direito público só pode existir enquanto refletir a forma jurídica privada na esfera da organização política, ou então deixa de ser direito" (PASUKANIS, I989, p. 75). 
O conceito pasukaniano de emancipação agora pode ser explicado mais claramente. Pasukanis argumenta que a sociedade capitalista é caracterizada por ser atomizada e permitir a acumulação de mercadorias, o que gera uma "cadeia ininterrupta de relações jurídicas”. Esse sujeito econômico egoísta (atomizado, que visa à acumulação e que se insere nas relações jurídicas) não é criado pela lei. Tampouco uma explicação puramente econômica pode fundamentar a existência de tal ser. É, assim, exatamente dessa forma de reprodução de vida, que é propriamente capitalista, que se faz necessária uma emancipação:

... quanto mais as relações mercantis e o incentivo do lucro forem sendo radicalmente suprimidos da esfera da produção, mais rápido soará a hora desta libertação definitiva de que Marx falou em seu ensino sobre A questão judaica:' somente quando o homem individual real recupera em si o cidadão abstrato e se converte, como homem individual, em sergenérico, em seu trabalho individual e em suas relações individuais; somente quando o homem tenha reconhecido e organizado suas forces propes como forças sociais e quando, portanto, já não separa de si a força social sob a forma de força política, somente então se processa a emancipação humana. (PASUKANIS, I989, p.I06 grifos e observações meus).

Portanto, a emancipação nessa passagem não é vista como emancipação somente do modo de produção capitalista (que se baseia na exploração da classe proletária), mas exatamente da superação da forma de reprodução da vida nos moldes da sociedade capitalista, ou seja, da superação também da forma jurídica enquanto tal e com a mudança da concepção de "homem individual" e "cidadão". A emancipação, ainda que dependa da superação do modo de produção capitalista, necessita de outros fatores: "A condição real da supressão da forma jurídica e da ideologia jurídica é um estado social no qual a contradição entre interesse individual e o interesse social esteja superada" (PASUKANIS, I989, p. 76).

A função prática do direito então, na sociedade capitalista, não por acaso a única que permite o máximo desenvolvimento da forma jurídica, não é senão a de fornecer as garantias necessárias para que os sujeitos econômicos egoístas dessa sociedade possam trocar entre si suas mercadorias. ${ }^{\text {II }}$ E sendo essa sua função fundamental, é ela que deve ser, em última instância, protegida pelos interesses de classe burgueses, não as abstrações decorrentes dela. O Estado de direito e as outras categorias ideológicas, em caso de questionamento da dominação burguesa,

II A importância da circulação da mercadoria (economia mercantil) é tão essencial para a caracterização da forma jurídica em Pasukanis, que o professor Naves, em seus estudos, aponta oito passagens de textos de autoria do pensador soviético que ilustram tal relação. op. cit., 2008, pp. 53-54. Não poderia ser diferente, considerando que esse é o modo pelo qual "Marx mostra ao mesmo tempo a condição fundamental, enraizada na estrutura econômica da própria sociedade, da existência da forma jurídica, isto é, da unificação dos diferentes rendimentos do trabalho segundo o princípio da troca de equivalentes.” (PASUKANIS, I989, p. 28) 
podem ser rapidamente colocados como relíquias históricas e o que se perceberia, nos termos pasukanianos, seria exatamente a continuidade da forma jurídica nas relações de troca, caso ainda se concebessem os indivíduos como sujeitos econômicos egoístas.

\section{Outra percepção do fenômeno jurídico. Emancipação em Neumann e a racionalidade jurídica.}

A exposição de Neumann, em The Rule of Law, é essencialmente marcada pela oposição entre o poder soberano estatal e a esfera de liberdades dos indivíduos frente ao Estado, as duas características básicas do Estado Moderno. Neumann tenta demonstrar como o direito, pensado em termos da oposição referida, desempenha um papel duplo em uma sociedade formalmente igual e materialmente desigual. Esse papel duplo corresponderia a que o "Império do Direito", pensado em termos de uma norma geral que limite a atividade do poder estatal, serve tanto como correspondente ao interesse de grupos ascendentes ao poder, como elemento desintegrador quando da conquista do poder por esses grupos ascendentes, dado que agora o poder a ser limitado é o da própria classe que se tornou hegemônica.

O "Império do Direito" deve ser pensado não em termos abstratos, como leis ou ordem impositiva do Estado, mas exatamente como um elemento constitutivo do Estado moderno e que se diferencia da soberania enquanto poder por permitir um raio de liberdades subjetivas. A análise se dá em dois planos: um em relação à evolução do conceito de direito no plano teórico, sendo que trabalha com autores como Cícero, Tomás de Aquino, Rousseau, Hobbes e Hegel; outro em relação à evolução da prática institucional e do contexto socioeconômico na Alemanha, Inglaterra e França, ${ }^{12}$ tendo em vista o papel desempenhado pelos conceitos jurídicos-políticos e a mútua influência entre ambos.

Do ponto de vista da história das ideias, há uma contraposição constante entre uma concepção política e outra racional em relação à soberania e ao direito.

Nos termos de Neumann, os teóricos da concepção política defenderiam que qualquer medida imposta por um Estado, no exercício de sua soberania,

I2 Tendo em vista os âmbitos deste trabalho, embora Neumann se preocupe em demonstrar a evolução histórica da prática institucional em relação aos conceitos jurídicos-políticos na Inglaterra, analisaremos somente esses aspectos na Alemanha, o que já nos permite trabalhar com o conceito de emancipação e com o papel do direito atribuído pelo autor na sociedade capitalista. 
seria direito. Assim, uma declaração de guerra ou lei que instituísse um imposto seriam formas jurídicas. No entanto, nem toda medida do Estado seria direito, segundo a concepção racional. Na realidade, só seria direito uma norma que contivesse um princípio de equidade para os seus receptores.

O direito natural (predomínio nos séculos XV, XVI, XVII), aproximando-se dessa última concepção, é, portanto, forma de expressão universal e geral (princípio de equidade) e, dessa forma, aponta na direção de novas demandas sociais e pode desempenhar papel revolucionário, nas situações em que a igualdade formal entre os indivíduos não existe.

Ocorre que, após o triunfo revolucionário, o direito natural perde influência conforme as noções de democracia e contrato social vão ganhando força ${ }^{13}$, ou seja, teorias positivistas. No entanto, a noção racional do direito não deixa de existir. Nesse instante, a conexão ocorre por meio da necessidade de três fatores, como apontado por Rousseau, para uma norma instituída pelo Estado ser direito: a generalidade da lei, a clareza da formulação (não permissão de cláusulas gerais, como boa-fé) e a não-retroatividade. Ou seja, há uma possibilidade de interferência do Estado na vida individual sendo que ao mesmo tempo em que se interfere é criado um espaço a partir do qual os cidadãos poderão exercer uma série de liberdades. Isso porque como a interferência deve ser geral - válida igualmente para todos - não pode existir regulação estatal individualizada.

Para Neumann, são quatro os tipos de liberdades criadas: individual (garantia de liberdade de religião e direito à moradia, por exemplo), política (liberdade de associação, de imprensa e de reunião, por exemplo), econômica (o principal direito é o da propriedade) e social (direitos que se desenvolveram a partir dos direitos econômicos e que visam à liberação da classe trabalhadora, como o direito à associação concedido aos sindicatos).

Em adição às liberdades criadas, surge também a possibilidade do Estado regular instituições jurídicas. "The legal institution can be defined as a bringing together, intended to endure, for the purpose of regulating the process of life and for their production and reproduction" (NEUMANN, I986, p. 40). Neumann se refere aqui às possíveis conexões entre homens, homens e propriedades e entre propriedades, de modo hierárquico ou não, cujos exemplos, dentre outros, são: fundação (propriedade que é uma instituição jurídica), sindicato (instituição jurídica entre homens) e fábrica (homens e propriedade).

I3 $\mathrm{O}$ direito natural muda de funções, na História: em um primeiro momento, é revolucionário, pois auxilia a ascensão política da classe burguesa ainda não hegemônica; porém, após ela se tornar hegemônica, o direito natural perde espaço para concepções positivistas, nas quais o que é direito válido é o direito estatal. 
Tanto os conceitos de liberdades quanto de instituições são importantes, pois eles se relacionam entre si e são os que tornam possível o papel desintegrador do status quo desempenhado pelo direito. Neumann constrói teoricamente a distinção entre liberdades ou instituições principais e liberdades ou instituições auxiliares. Uma liberdade principal pode estar rodeada de instituições e liberdades auxiliares que possibilitam sua maior efetivação. Do mesmo modo, uma instituição principal pode estar cercada de instituições e liberdades auxiliares para o cumprimento de sua função. ${ }^{\text {I4 }}$

A questão é essencial, pois em determinados momentos históricos as liberdades e instituições auxiliares que antes contribuíram para a efetivação da liberdade ou instituição principal, podem se tornar prejudiciais e começarem a comprometer seu desenvolvimento. No entanto, antes de analisarmos essa característica, é válido ressaltarmos o estudo de Neumann referente ao papel desempenhado pelos conceitos jurídico políticos na prática institucional e o contexto socioeconômico da Alemanha.

É no capítulo I3 de sua obra que Neumann demonstra como na Alemanha do século XIX o liberalismo econômico e os interesses econômicos da classe burguesa alemã foram implementados por meio não do domínio político da burguesia, mas por meio da aplicação de leis gerais propostas pelo parlamento (que era composto tanto pela nobreza quanto pelos burgueses, daí a não hegemonia) por juízes independentes. Essa forma de predomínio (leis gerais e juízes independentes, oriundos da classe média e dispostos a decidir conforme os interesses burgueses), só é possível em um dado contexto do capitalismo: o capitalismo competitivo, no qual haveria certa competição entre os burgueses, individualmente, mas que o interesse da classe burguesa como um todo (igualdade formal, liberdade para contratar, a propriedade privada dos meios de produção, entre outros) fosse garantido pelo aparato estatal.

A generalidade da lei desempenhava três funções basicamente: a) caráter ético: garantindo um mínimo de liberdade e igualdade; b) encobrimento da dominação: a lei geral não dá relevância ao fato de que ainda que as partes sejam formalmente iguais, materialmente são desiguais, não permitindo igualdade de oportunidades no momento da celebração de um contrato, por exemplo; c) calculabilidade e a previsibilidade, que se constituem pelo fato de que a lei geral é o máximo de racionalidade formal e permite que a burguesia saiba qual o direcionamento estatal. Por sua vez, a independência dos juízes é essencial no caso específico dos alemães, pois se a burguesia não pode dominar

I4 No entanto, no momento da análise global das instituições e liberdades, percebe-se que "every liberty, therefore, appears both as a main and as an auxiliary one, just as a legal institution appears at the same time supplementary as main" (NEUMANN, I986, p. 42). 
diretamente por meio de leis gerais (considerando que não domina completamente o processo político, dada a influência da nobreza), pode determinar suas interpretações. ${ }^{15}$

No entanto, a racionalidade da lei, garantida pela sua generalidade, pode ser utilizada para favorecer uma classe autoconsciente de si e que demande sua participação na vida política do Estado, por exemplo, a classe trabalhadora.

Enquanto nos moldes de um liberalismo clássico o conflito de classes é negado, por se acreditar na suficiência da igualdade e liberdade formais dos indivíduos - além de esse tipo de visão favorecer a classe hegemônica - no momento da formação da Constituição de Weimar (I9I9), uma democracia pluralista foi instituída e reconheceu-se essa luta, tentando-se promover uma cooperação entre as classes por meio da ideia de paridade.

Especificamente, na República de Weimar, Neumann concebe todo o sistema formado a partir da Constituição como:

This whole system of parity ought to be called a system of collectivist democracy, which means that the state for the fulfillment of its tasks uses private organisations, and gives them a share in political power. The state acts between the two negotiating and collaborating parties as a neutral third, which should interfere only in the social opponents do not reach agreement (NEUMANN, I986, p. 27I).

Para ser possível essa cooperação entre as classes, é necessário que a massa trabalhadora se torne politicamente consciente e que haja um efetivo equilíbrio entre as forças classistas, o que impossibilitaria a hegemonia de uma delas. As instituições constitucionais, como o sufrágio e os direitos sociais são responsáveis, na visão de Neumann, por permitir tal equilíbrio.

Ocorre que, em âmbito econômico, o capitalismo competitivo não era mais possível. Uma tendência à monopolização, considerando a necessidade de corte de custos e da segurança dos mercados, era tão presente que autores se referem à época como capitalismo monopolista.

Essas duas características - democracia coletivista e capitalismo monopolista - reforçavam o poder do governo (burocracia ministerial) em relação ao Parlamento. Principalmente por conta dos governos que surgiram em tal período serem de coalizão, caso contrário seria impossível formar uma maioria, era ainda mais difícil que os deputados eleitos se opusessem por meio do veto às decisões da burocracia.

I5 Deve-se ter em mente que tal império da lei geral nunca existiu completamente no capitalismo competitivo. Medidas de força e as "cláusulas gerais", que trazem um aspecto de irracionalidade por não serem previsíveis nem calculáveis, sempre existiram em menor ou maior grau. 
No campo jurídico, tal contexto provoca a centralidade das cláusulas gerais $^{16}$ : na década de 20 é a expressão do acordo de classes rumo à cooperação. ${ }^{17}$ Como há paridade entre as classes no corpo político, é impossível se conceber uma lei geral com formulação clara e objetiva, pois os interesses expostos são antagônicos. Apela-se então para as cláusulas gerais, que podem ser utilizadas conforme o contexto de uma forma ou de outra. ${ }^{18}$ No entanto, a partir do início da década de 30, com a ascensão de Hitler ao poder, percebe-se a ideia de paridade como pura ideologia e as cláusulas gerais se tornam mecanismos para favorecimento dos interesses do capital monopolista, que influencia facilmente a burocracia governamental.

Isso leva ao diagnóstico de que a sociedade em que existiu de fato um equilíbrio entre as classes, e na qual o Estado surge como um terceiro neutro, foi historicamente instável e existiu por breve espaço de tempo. Uma década de aplicação da Constituição de Weimar foi o período suficiente para a ascensão do nazismo.

No estudo de Neumann, esse novo período é essencialmente marcado pela continuação da calculabilidade nos processos de troca, servindo ao interesse dos monopolistas, porém as demais características do direito são colocadas em segundo plano, sendo o próprio fenômeno jurídico caracterizado como o que "é útil para a Alemanha”. Tal definição, sem dúvida, não condiz com o desenvolvimento histórico da concepção racional de direito, levando Neumann a concluir dizendo que "law does not exist in Germany, because law is now exclusively a technique of transformating the political will of the Leader into constitutional reality" (NEUMANN, I986, p. 298).

Assim, pode-se compreender melhor a evolução do conceito de direito na sociedade capitalista e o conceito de emancipação para Neumann. Como fica claro, o direito desempenha funções essenciais para o desenvolvimento do capitalismo, em uma perspectiva histórica. ${ }^{19}$ A calculabilidade/previsibilidade e o fato de funcionar como velador do domínio de classes fazem que o fenôme-

I6 Normas brancas, como a necessidade de guardar "boa-fé" no momento da celebração dos contratos, ou dizer que uma greve só é válida se não atentar aos "bons costumes”.

I7 Neumann chega a utilizar as decisões da Corte Federal do Trabalho para explicitar como a utilização das "cláusulas gerais" tinha o objetivo de efetivar o compromisso entre as classes.

I8 Deve-se atentar para a maior relevância do papel do juiz e da interpretação a partir do momento da centralização das cláusulas gerais, nas quais a disputa por uma interpretação é ainda maior que nos casos de normas gerais.

I9 É evidente, portanto, que o direito não é condição indispensável para o modo de produção capitalista funcionar, caso contrário, não se poderia dizer que o Estado alemão sob o nazismo era o capitalismo sem direito. 
no jurídico seja necessário para o pleno desenvolvimento das forças produtivas capitalistas.

Ocorre que a possibilidade de o direito se realizar nos termos da concepção racional provoca igualmente o surgimento de uma esfera de liberdades subjetivas, das quais fazem parte liberdades e instituições principais e auxiliares, que da mesma forma que são essenciais ao capitalismo (liberdade de contratar, liberdade de comércio etc.) podem abrir espaço para uma classe explorada e autoconsciente de sua condição tentar transformar as condições que a impõe essa situação, usufruindo as possibilidades que se apresentam no interior dessa própria sociedade (momento da formação da Constituição de Weimar).

Referindo-se, explicitamente, aos quatro tipos de liberdades criadas pelo direito no Estado Moderno:

[...] we take decisively the view that such a connection between the rights to personal, political, and social freedom on the one hand, and the rights to economic freedom which have developed only within a competitive economic system on the other, does not in fact exist. Even a very superficial historical analysis teaches us that at least personal and political rights have existed and even been struggled for long before the competitive economic system arose. It can be proved that the function of these rights is not lost, but tends rather to increase in importance after the disappearance of free competition (NEUMANN, I986, p. 38).

Partindo da distinção entre forças produtivas e relações de produção, Neumann defende que do mesmo modo que após o desenvolvimento das forças produtivas em uma determinada sociedade as relações de produção entram em contradição com elas e ocorre uma transição de uma ordem social para outra, do feudalismo para o capitalismo, por exemplo, pode-se verificar o mesmo fenômeno no interior de uma ordem social, como quando da transição do capitalismo competitivo para o capitalismo monopolista. Em um primeiro momento, a liberdade de contratar e a liberdade de comércio "são meios para a realização do lucro para o proprietário dos meios de produção" (NEUMANN, I986, p.44). ${ }^{20}$ Após a transição para uma economia capitalista, a liberdade de comércio possibilita a inserção de competidores que podem ameaçar a estabilidade dos monopolistas. Da mesma forma, a liberdade de contrato pode permitir que os indivíduos se mantenham afastados dessas organizações monopolistas e contratem somente com os novos competidores. Nessa análise,

20 Tradução livre do original: "are means for the realisation of profit for the owner of the means of production". 
duas liberdades suplementares à liberdade principal da propriedade, que antes eram auxiliares, tornam-se empecilhos.

Neumann tenta demonstrar que uma análise do todo social do capitalismo deve levar em consideração tais alterações para que seja possível utilizar o direito como ferramenta para diversas reivindicações. Por exemplo, perceber que, no capitalismo monopolista, o império da norma geral sofre uma constante ameaça e que a racionalidade do direito está em xeque, colocando sob risco diversas liberdades e instituições que trouxeram benefícios inclusive para a classe trabalhadora, por exemplo, como a possibilidade de se associar por meio de um sindicato.

Acrescenta-se a isso o fato de Neumann ter vivenciado a situação da Alemanha nazista e os horrores causados pela subversão da racionalidade jurídica em puro decisionismo. Esses motivos são suficientes para o autor defender em sua obra que os ganhos materiais ${ }^{21}$ oriundos da concepção racional do direito não podem ser ignorados por defensores de uma sociedade emancipada.

Acredito que é a partir desse contexto que devem ser compreendidas as suas afirmações, como: "a sociedade socialista terá que obter recurso da instituição do ato administrativo - isto é, da regulação compulsória pertencente ao direito público" (NEUMANN, I986, p.I8), "sem uma alteração decisiva do sistema jurídico a realização de uma sociedade socialista é impossível" (NEUMANN, I986, p.I8). ${ }^{22}$ Não significando que uma sociedade emancipada necessariamente terá a forma jurídica como garantidora da efetiva igualdade e liberdade dos indivíduos, no entanto, não acreditando que a supressão da racionalidade do direito seja positiva para o desenvolvimento de tal sociedade.

\section{Possível diálogo entre Neumann e Pasukanis.}

Do exposto, fica clara a preocupação de Pasukanis em historicizar o fenômeno jurídico. A relação entre forma jurídica e forma da circulação de mercadorias, e a importância da mediação por meio do princípio da equivalência, mostram a necessária superação da forma jurídica quando do desenvolvimento das forças produtivas de uma determinada sociedade que conduza ao fim desse modo de produção da vida, qual seja, o que transforma o trabalho em

2I Por exemplo: não possibilidade de se exercer exploração de minorias, por meio da exigência da generalidade da lei, não retroatividade das leis, o exercício do poder de forma não despótica ou arbitrária, de modo geral.

22 Traduções livres de: "Therefore, the socialist society, too, will have to take recourse to the institution of the administrative act - i.e. to compulsory regulation belonging to public law." E "without a decisive alteration of the legal system the attainment of a socialist society is impossible". 
Comparação entre a função do direito nas obras Teoria Geral do Direito...

mercadoria. Realizar essa conexão fundamental permite evidenciar tanto as funções ideológicas como as funções objetivas que o direito assume no interior da sociedade capitalista. No entanto, fica a questão: como lidar com o aparato jurídico-estatal em um momento transitório para uma sociedade emancipada? Defender que o Estado de Direito, com suas garantias fundamentais, tenha somente um caráter ideológico é correto? Acredito que Pasukanis não visava responder a essas perguntas quando da formulação de suas principais teses para o livro Teoria Geral do Direito e o Marxismo:

De qualquer maneira, o presente trabalho não pretende ser de jeito nenhum o fio de Ariadne marxista no domínio da teoria geral do direito; ao contrário, pois em grande parte foi escrito objetivando o esclarecimento pessoal. De onde a abstração e a forma concisa e mesmo assim apenas esboço de exposição; de onde também o seus aspecto unilateral que se deve inevitavelmente à concentração da atenção sobre determinados aspectos do problema que se revelam essenciais (PASUKANIS, I989, p.I, grifos meus).

Por sua vez, o que Neumann tenta demonstrar é que mudanças históricas como o sufrágio universal e a mudança de capitalismo competitivo para capitalismo monopolista podem ter consequências significativas para o desenvolvimento da autoconsciência da classe trabalhadora em uma sociedade capitalista e para uma práxis emancipatória no interior dessa sociedade. Na realidade, não acredito que Neumann discordaria de Pasukanis quanto a historicização do fenômeno jurídico. Ele não desenvolveu o tema, pois isso não estava nos limites de suas preocupações ao trabalhar com o direito. Suas preocupações eram de demonstrar como a concepção racional do direito, que foi essencial para o desenvolvimento do capitalismo competitivo, trazia em seu interior possibilidades de criação de conflitos políticos - por exemplo, a possibilidade de participar do parlamento ou da interpretação de cláusulas gerais - e como o capitalismo monopolista poderia sobreviver com a supressão da racionalidade jurídica (tentativa de equacionar a questão levantada pelo Estado nazista). ${ }^{23}$

Neumann, dessa forma, permite trabalhar com o conceito de emancipação enquanto a supressão da propriedade dos meios de produção, porém, no interior da forma jurídica e com a pluralidade de visões, pois, caso contrário, haveria possibilidade real de convivermos com uma realidade fascista. Pasukanis,

23 Uma racionalidade do poder não precisa advir necessariamente do direito. No entanto, Neumann vê que a racionalidade jurídica serve como proteção a um exercício arbitrário e autoritário. A luta pela sociedade emancipada ocorre necessariamente por meio da racionalidade do poder, que para Neumann, advém da racionalidade jurídica, enquanto para Pasukanis, advém do fato de o Estado estar sob a hegemonia da classe proletária. 
por viver em um contexto no qual a "ditadura do proletariado" já se encontrava presente (ou seja, a racionalidade no exercício do poder advém dessa condição, e não da limitação da atividade estatal por normas gerais), não possui a preocupação de perder a luta pelo Estado para a classe burguesa. No entanto, não foi exatamente essa "ditadura do proletariado", com o desrespeito a alguns princípios jurídicos que imprimiam racionalidade ao aparato estatal, que pode ter permitido os erros e abusos stalinistas?

Talvez a leitura conjunta de ambas as obras permita chegar às seguintes conclusões: enquanto Pasukanis contribui com a crítica da filosofia do direito ao traçar a dinâmica do fenômeno jurídico enquanto produto histórico, buscando evidenciar os limites inerentes ao direito em uma sociedade comunista, como nas palavras de Mészaros:

em uma "fase mais adiantada da sociedade comunista", quando - sob a premissa do mais alto desenvolvimento proporcional a elas - a sociedade obtém, "de cada um de acordo com sua habilidade" e dá "a cada um de acordo com as suas necessidades", a necessidade de aplicação de um padrão igual não existe mais, uma vez que o desenvolvimento completo de um indivíduo de modo algum interfere na autorrealização dos outros como indivíduos verdadeiros. Sob tais circunstâncias - quando a divisão do trabalho e o Estado estiverem suplantados - a questão da efetivação de direitos (mesmo que sejam direitos humanos) não pode nem precisa emergir, uma vez que o "livre desenvolvimento das individualidades" (que nas formas anteriores de desenvolvimento social, incluindo a sociedade de transição, só poderia ser postulado de forma mais ou menos abstrata) é integrante do metabolismo social e atua como seu princípio regulador fundamental (Mészaros, 2006, p. I68).

Neumann formula uma crítica que valoriza a racionalidade jurídica, sem entretanto desconsiderar questões essenciais do direito, como sua historicidade. Tanto estava atento às contingências históricas do fenômeno jurídico que, ao descrevê-lo, utiliza uma série de elementos "extrajurídicos", inclusive detalhando a ascensão e declínio de postulados jurídicos na história e em determinadas sociedades, como no caso do direito natural. No entanto, ao realizar a crítica do Estado nazista e do próprio direito, limita-se (o que, faça-se à ressalva tendo em vista a obra do autor, não é pouco) a se posicionar, evidentemente, ao lado de uma concepção racional do direito. ${ }^{24}$ Essa defesa, ainda que não contribua para a historicização do direito enquanto categoria histórica, contribui para

24 Não se pode descartar a hipótese que esse era um posicionamento político tendo em vista os rumos tomados pela República de Weimar, no começo da década de 30. No entanto, tendo em vista os objetivos do presente estudo e a demanda por pesquisa historiográfica que demandaria a comprovação de tal proposição, deixe-se apontada tal hipótese dessa forma, sem mais. 
a conquista de uma sociedade emancipada (que em The Rule of Law, não deixou de ser o objetivo de Neumann) sem o apelo à luta armada, considerando sua contribuição em termos de como é importante à classe explorada se tornar autoconsciente de sua condição social e reivindicar para si o papel de elemento integrador do conjunto da sociedade, como Marx já deixava claro ao escrever que o proletariado era capaz de realizar a emancipação humana universal por ser a classe universal. Neumann, percebendo as qualidades da racionalidade jurídica, permite que se busque na sociedade emancipada não a derrota da classe exploradora, mas a emancipação de todos os indivíduos, fazendo com que cada um possa desenvolver livremente suas individualidades.

\section{Referências bibliográficas.}

CASALINO, Vinícius Gomes. A teoria do direito de Pachukanis e pseudoconcreticidade: uma contribuição à crítica marxista do direito. Dissertação (Mestrado em direito). Faculdade de Direito da Universidade de São Paulo, São Paulo: 2007.

GOLLINS, Hugh. Marxism and Law. Oxford: Glarendon Press, $200 \mathrm{I}$.

MÉSZÁROS, István. Filosofia, Ideologia e ciência social. São Paulo: Boitempo Editorial, 2008.

NAVES, Márcio Bilharinho. Marxismo e direito: um estudo sobre Pachukanis. São Paulo: Boitempo Editorial, 2000.

NEUMANN, Franz. The Rule of Law. Leamington Spa: Berg Publishers, I986.

PASUKANIS, Eugenyi. Teoria geral do direito e o marxismo. Trad. Paulo Bessa. Rio de Janeiro: Renovar, I989.

RODRIGUEZ, José Rodrigo. Franz Neumann, o direito e a Teoria Crítica in Lua Nova, n. ${ }^{\circ}$ 6I. São Paulo, 2004.

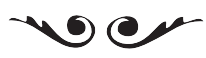

Flavio Marques Prol é graduando em Direito pela USP.

E-mail: fmprol5@hotmail.com 